\title{
Approach to the construction of specialized portable terminals for monitoring and controlling technological equipment
}

\author{
Petr Nikishechkin ${ }^{1, *}$, Nadezhda Chervonnova ${ }^{1}$, and Anatoly Nikich ${ }^{1}$ \\ ${ }^{1}$ MSTU «STANKIN», Moscow, Russia
}

\begin{abstract}
The work deals with the features of construction of humancomputer interaction to manage the complex process equipment. The mechanism for creating additional portable terminals for monitoring and controlling complex machine tools is presented. A practical example of using the mechanism for creating additional terminal solutions for monitoring and controlling the Quaser MV184P milling machining center is given.
\end{abstract}

\section{Introduction}

Modern trends in the industry include increasing the level of automation and computerization of all processes and the creation of multi-level, global technological and organizational system, which involves the integration into a single information space of all technological operations and their accompanying processes. Portable, mobile devices for monitoring and managing technological processes are increasingly being integrated into the industry, and cloud storage technologies are used to store and access large amounts of data.

Management of complex machine tools is usually carried out with the help of numerical control systems (CNC), which are a complex of hardware components, built-in mathematical and logical control algorithms, as well as human-computer interaction tools. For such systems, designing the operator interface from scratch for each control object is impossible due to the complexity of the software implementation. Therefore, to solve the problems of human-machine interaction in the management of machine equipment and robotic complexes, the company uses standard terminal solutions (operator panel, machine toolbar), the set of which is usually defined in advance by the system manufacturer, has limited and sufficient functionality, and does not provide the ability to change it. At the same time, the development of modern production technologies and industrial equipment also leads to an increase in the amount of data that must be controlled in the management of technological processes. Often, these staff terminal means is not enough for full control and management of complex processes, especially when the equipment is complex electroautomatics that require visualization and control of a large number of parameters. It also presents a problem when machining equipment has large dimensions that require portability of terminal solutions. In this regard, one of the most important tasks is the

*Corresponding author: pnikishechkin@gmail.com 
implementation of the user interface of control systems, which allows you to analyze all the necessary spectrum of data transmitted from control objects and react quickly to different situations. Thus, the actual task is to create mechanisms for constructing additional portable terminals with a convenient and flexible user interface designed to solve the tasks of monitoring and controlling technological equipment. In this case, the graphic objects of the operator interface must have a connection with the main basic control system and receive all necessary data from the control object. This is especially relevant for the management of equipment of increased complexity, which are CNC machines [1-3].

The closest analogue of the described task are SCADA (Supervisory Control And Data Acquisition) systems - these are software products that are designed to support the collection, processing, display and archiving of information about the object in real time. SCADA is a comprehensive software product that allows the implementation of data collection and analysis at the upper levels of management (usually at the shop floor level) directly to engineer-designers of control systems. This is a powerful and multifunctional software product, but it has its drawbacks, among which one can note: the high cost of SCADA, which in turn increases the cost of the control system; closed at the level of the end user, which does not allow the implementation of their own algorithms for processing information. In this regard, for inexpensive logical control systems that ensure the coordinated operation of nodes and aggregates of simple control objects, it is advisable to develop our own system for implementing the operator interface on the basis of a set of standard graphic objects [4-6].

The article presents the theoretical aspects of developing a mechanism for creating flexible and mutable operator interfaces for the implementation of management of heterogeneous technological equipment; practical aspects of development of the design environment and software support of the user interface, as well as tools for monitoring the operation of technological equipment and an example of its use.

\section{Development of the mechanism for creating additional terminal to manage and control the operation of machine tools}

The basic computer-control platform developed at the Department of «Computer Control Systems» allows solving a wide range of industrial automation tasks. The main product built on the basis of this platform is the CNC system "AxiOMA Control», which allows controlling complex machine tools of various types. The implementation of the CNC system is executed on a modular basis, which allows to exclude or, conversely, add a certain functionality of the system for solving problems of varying complexity. The CNC system also includes a built-in software-implemented controller that allows to solve problems of controlling the machine's electroautomatics [7]. The CNC system «AxiOMA Control» has a two-computer architecture and consists of the core of the system, operating in hard real-time and performing all the computing and control functions. The terminal part provides functionality for human-machine interaction and works in computer time. As a terminal, customized solutions are usually used in the form of an operator panel and a machine toolbar. The article proposes the creation of a mechanism for the development of additional, including mobile terminal solutions that interact with the core of the CNC system, which allow visualizing information on the operation of the main components of the process equipment and the parameters of the CNC system. Structural model, visualizing the principle of integration of additional terminal solutions, is shown in Fig. 1. 


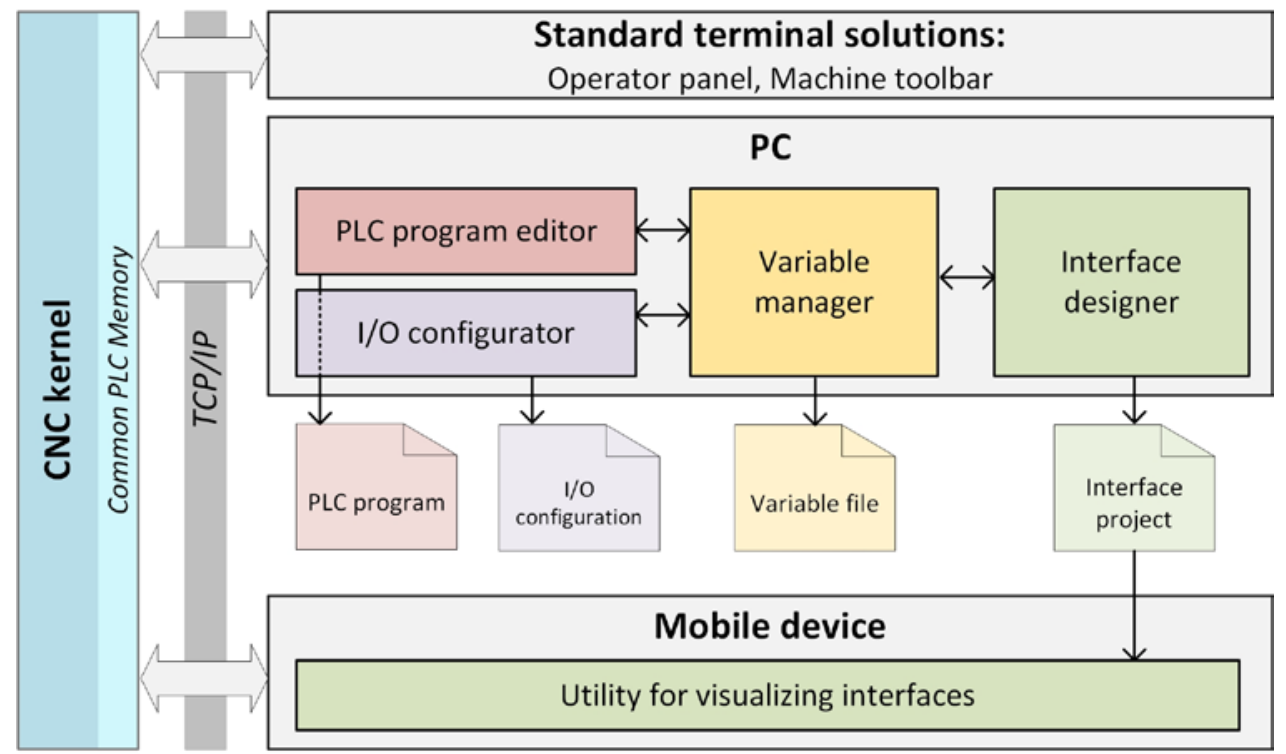

Fig. 1. Structural model of interaction of the $\mathrm{CNC}$ system with additional terminal solutions

The interaction between the terminal part and the core of the CNC system is realized through the communication client. It provides data transfer between the remote / remote terminal and the core of the control system using the TCP / IP protocol: via an Ethernet connection or a wireless connection (Wi-Fi). One of the ways to transfer basic information between the kernel and the terminal part of the system is the shared memory mechanism, which is the allocated memory area in the core of the system. It pre-allocates cells, which stores information about the status of the controller I/ O, as well as the values of user variables, which include basic information about the operation of the CNC system. This memory area is available to terminal clients for recording their own output signals and reading the necessary input information. The described method of data exchange is the fastest between the processes of the kernel and terminal solutions, and it allows to provide cross-platform, that is, independence from the operating system on which the kernel or interface functions (Windows OS / Linux OS). It is assumed that the basic information needed for the transfer of additional terminal clients, is information about the work of the PLC, i.e. the status of all inputs / outputs controlled by an embedded controller, as well as basic information about the work of the $\mathrm{CNC}$ system: work status, the provisions of the axes, the speed and magnitude of feed at processing [8].

Creation of control algorithms for machine electroautomatics is implemented in a specialized PLC editor, which allows creating programs in the FBD language. The I / O device configurator configures and parameterizes the hardware of the controller, I / O devices, and servo drives. After the development of the program and the configuration of the hardware devices, a set of main variables is systematized, which must be visually monitored or controlled by their values, using a special PLC variables manager (Fig.2). 
吗 Управление переменными ПЛК

\begin{tabular}{|c|c|c|c|c|c|c|c|c|c|}
\hline ID & $\begin{array}{l}\text { Тольк } \\
\text { дляя } \\
\text { чтени }\end{array}$ & Имя & Описание переменной & Тип значения & & $\begin{array}{l}\text { Anpec } \\
\text { байта }\end{array}$ & $\begin{array}{l}U_{H A} \\
\text { бит }\end{array}$ & & Значение \\
\hline 51 & $\nabla$ & Wm_CoolSpndl & Авария СОЖ через шпиндель & Битовый & 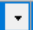 & 104403 & 6 & $\cdot$ & \\
\hline 52 & $\square$ & Wm_LowCoolspnd & Низкий уровень СОЖ через шпиндель & Битовый & 一 & 104403 & 7 & . & \\
\hline 53 & $\square$ & WmHighCoolSpnd & Высокий уровень СОЖ через шпиндель & Битовый & - & 104404 & 0 & - & \\
\hline 54 & $\square$ & PrgRun & & Битовый & - & 104400 & 3 & . & \\
\hline 55 & $\square$ & Spndl_run & & Битовый & - & 104400 & 0 & - & \\
\hline 56 & $\square$ & CoolantSpnd & СОЖ через шпиндель & Битовый & - & 104408 & 1 & - & \\
\hline 57 & $\square$ & CoolantSpndl & & Битовый & $\cdot$ & 104408 & 1 & $\cdot$ & \\
\hline 58 & $\square$ & M3key & & Битовый & - & 272 & 0 & • & \\
\hline 59 & $\square$ & Coolfilter & & Битовый & • & 204809 & 0 & $\cdot$ & \\
\hline 60 & $\square$ & CoolantSpndl & СОЖ через шпиндель включен (с встроенным фи... & Битовый & - & 104408 & 1 & $\cdot$ & \\
\hline 61 & $\square$ & ON_Shneki & Включить шнеки & Битовый & • & 104408 & 2 & $\cdot$ & \\
\hline 62 & $\square$ & MDI_mode & & Битовый & • & 104401 & 6 & $\cdot$ & \\
\hline 63 & $\square$ & AUTO_mode & & Битовый & • & 104401 & 2 & • & \\
\hline 64 & $\nabla$ & Not_JOG_mode & HE Jog режим в ЧПУ & Битовый & $\cdot$ & 104401 & 5 & $\cdot$ & \\
\hline 65 & $\square$ & M110_finished & успешное выполнение M110 & Битовый & $\cdot$ & 104410 & 6 & $\cdot$ & \\
\hline 66 & $\square$ & WmShekRight & Авария шнек направо & Битовый & - & 104404 & 1 & $\cdot$ & \\
\hline 67 & $\square$ & WmShekLeft & Авария шнек налево & Битовый & $\cdot$ & 104404 & 2 & $\cdot$ & \\
\hline 68 & $\square$ & WmShekRight & & Битовый & • & 104404 & 1 & . & \\
\hline 69 & $\square$ & WmShekLeft & & Битовый & $\cdot$ & 104404 & 1 & . & \\
\hline 70 & $\square$ & WmShekLeft & & Битовый & • & 104404 & 2 & . & \\
\hline 71 & $\square$ & BtnEmStop & Кнопка аварийного останова нажата & Битовый & - & 104406 & 3 & - & \\
\hline
\end{tabular}

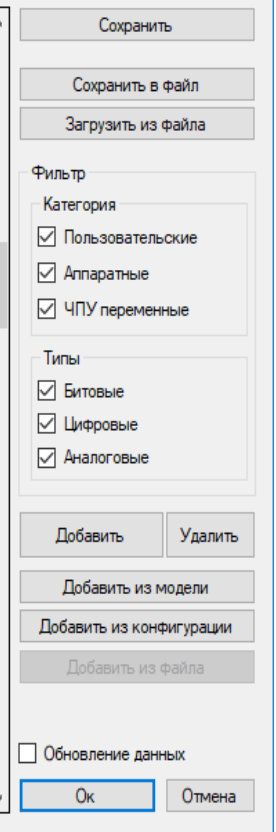

Fig. 2. The screen for creating and configuring PLC variables.

Each variable has its own set of characteristics, including its description for the operator, the type of the stored value (bit / integer / floating point), and the address in the shared memory area, specified by specifying the address of the byte and the bit to which the variable is bound. Variables also belong to one of three categories: user, hardware (corresponding to inputs / outputs) and $\mathrm{NC}$ variables (contain information about the operation of the system). Using a similar set of variables, it is possible to create additional terminal solutions that visualize their values and allow them to change in order to control the process and manage it. Creation of a visual part of additional terminal solutions is carried out with the help of a special designed interface designer.

The designer allows you to visually locate the necessary visual components and perform their parameterization, that is, the binding to the PLC variables described above. The set of visual components includes elements for monitoring the parameters of the controlled process (labels, indicators), as well as components for process control (buttons, regulators, value entry fields).

The terminal interface constructor contains:

- the component panel, which contains the main objects that the operator can create to manage or monitor the process;

- the area where the terminal solution is created - the main window in which the operator interface is created;

- the terminal settings panel - the area in which you configure the visual display of each component and specify the settings for their binding to the memory areas of the system's core. 


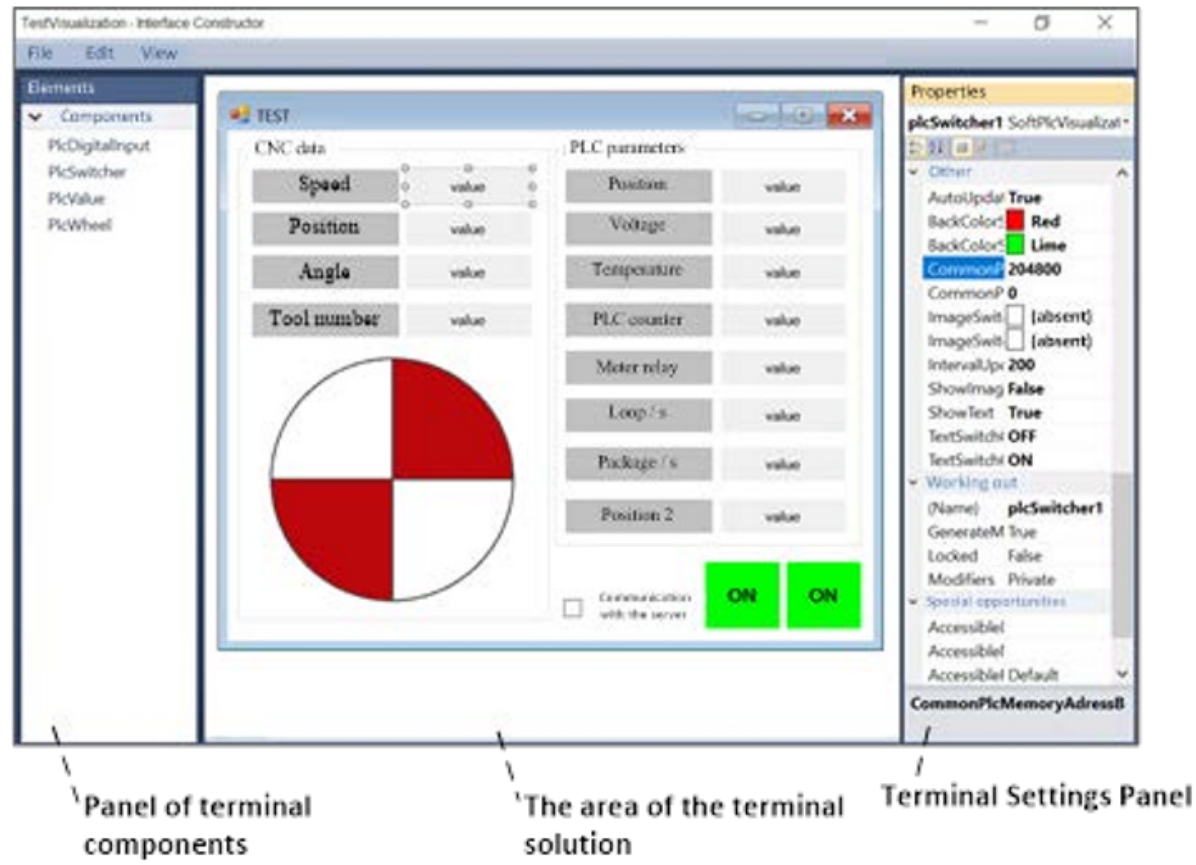

Fig. 3. Terminal solutions development environment.

In this example, we use PlcValue objects that are intended to display the status of both the bit variables (true / false) and variables with numeric values. In addition, in this example, the PlcSwitcher component is used to enable the bit signals to be output to the controller outputs, as well as the PlcWheel component to visually display the position and speed of the object of rotation (for example, a rotary axis).

The binding of visual components to the values of PLC variables can be made either manually by specifying the shared memory address, or automatically, by binding to a specific variable from the corresponding table in the PLC editor. After creating the terminal components and their parameterization, the interface project is saved to a special file.

Reproduction of the developed interface design is carried out with the help of a specially developed utility that allows displaying the created operator interface with reference to the values from the memory areas of the system kernel. In this way, it is possible to create additional control over the state of operation of individual units of technological equipment, as well as obtain information on the operation of the control system.

Development of the operator interface for additional terminal devices for the Quaser MV184P milling machining center

As a practical application of the developed mechanism, the Quaser MV184P milling machining center with three linear axis of movement and controlled by the CNC system «AxiOMA Control» was chosen. Fig. 4 shows the general view of the machining center, where its main components and the most important nodes of the electroautomatics are selected, whose operation is to be monitored during operation. 


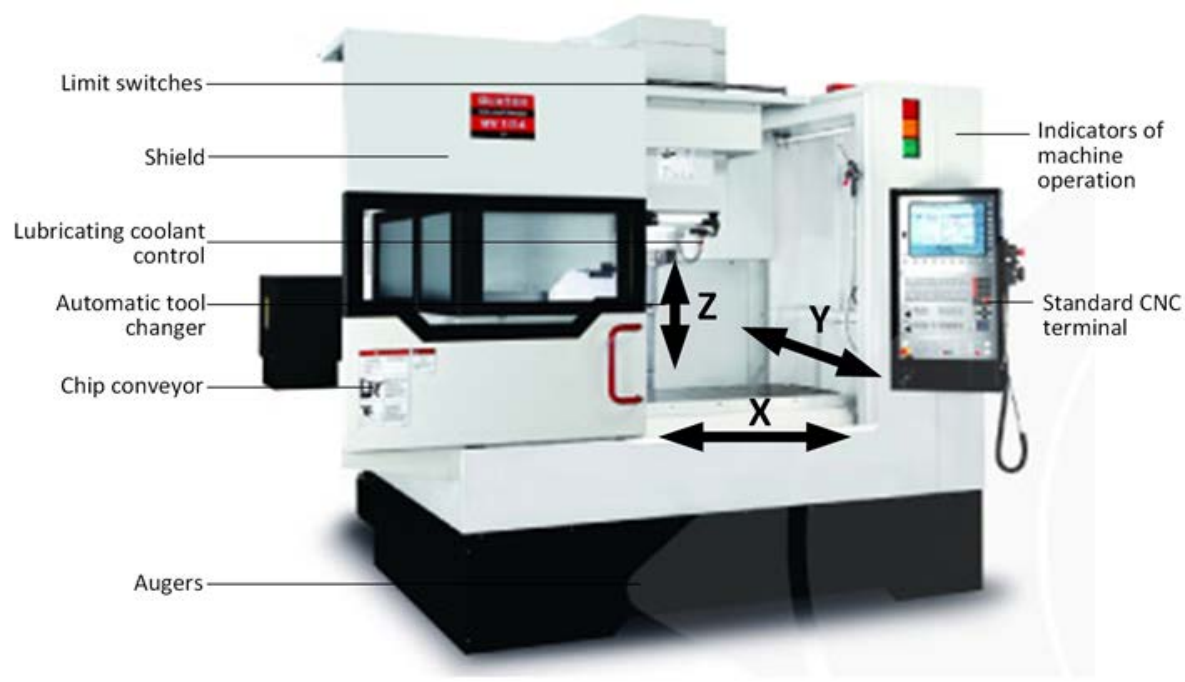

Fig. 4. Machining center Quaser MV184P.

Information that needs to be monitored is systematized:

- power control: general power supply, drive supply, emergency stop signal;

- the status of the machine ("traffic light");

- control of limit switches along the axes;

- work of the chip removal augers;

- control of the operation of the cutting fluid supply control;

- control of the mechanism of automatic tool change;

- monitoring the operation of protective fences.

In addition to monitoring the operation of the machine's electrical machine, it is advisable to output basic information about the operation of the system to the additional mobile terminal, namely, the status of the feed drives, the current position and the speed. To obtain and visualize this information, $\mathrm{NC}$ variables are used $[9,10]$.

When creating the terminal solution, the main components described earlier were linked to the corresponding memory areas of the basic variables of the control program, which are responsible for the state of all the listed nodes.

In addition to visualizing the work of the electroautomatics equipment of the machining center, information on its linear axes $(\mathrm{X}, \mathrm{Y}, \mathrm{Z})$ is displayed in text: the status of the servo drives corresponding to them, the current position of the axis and the speed of its movement (Fig.5). 


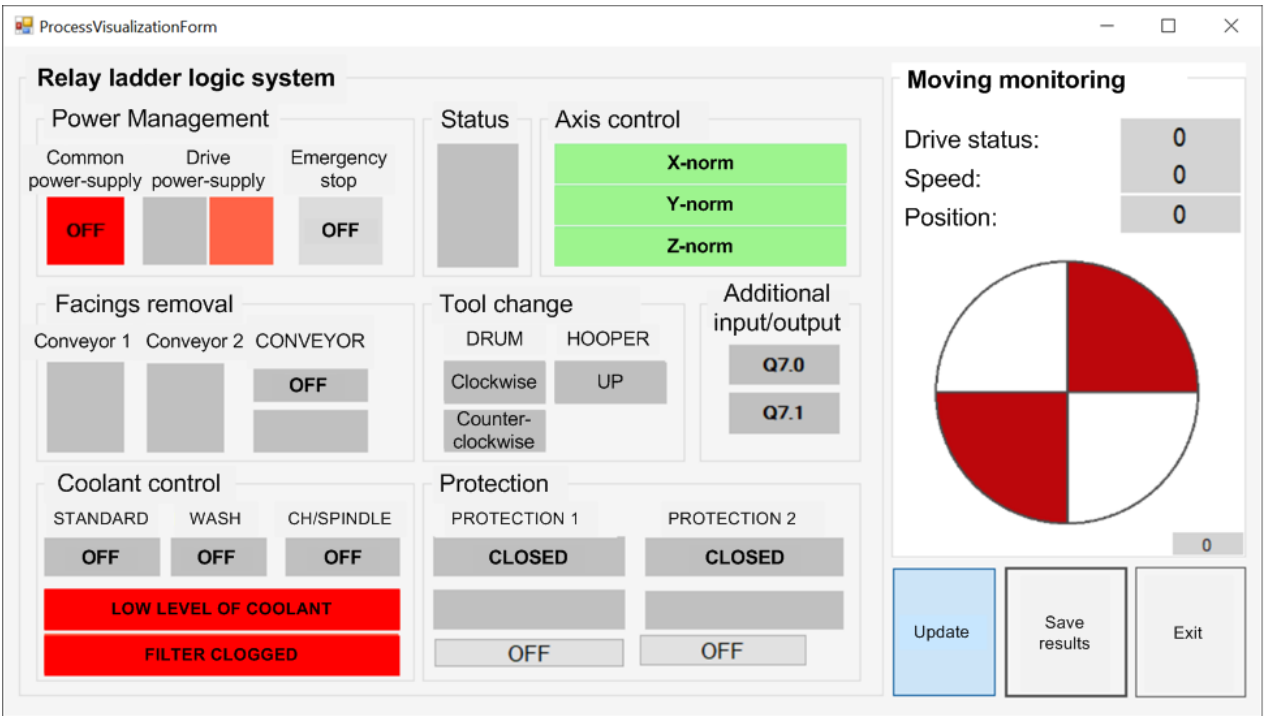

Fig. 5. View of the interface of the additional terminal solution for monitoring the operation of the main components of the milling machining center

To test the operation of the terminal solution, as well as debugging the operation of the control algorithms, a training and demonstration stand was designed (Fig. 6) simulating the operation of the main centers of the milling center. By means of the buttons on the stand, it is possible to simulate a change in the state of operation of various parts of the machine's electroautomatics. The outputs of the electroautomatics are simulated with the help of LEDs. The stand contains the same control and monitoring elements as the developed terminal solution: the presence of power supply, emergency button operation, status display, operation of the tool changer, safety guards, coolant management, chip removal augers, as well as control over the axes outside the limits working area.

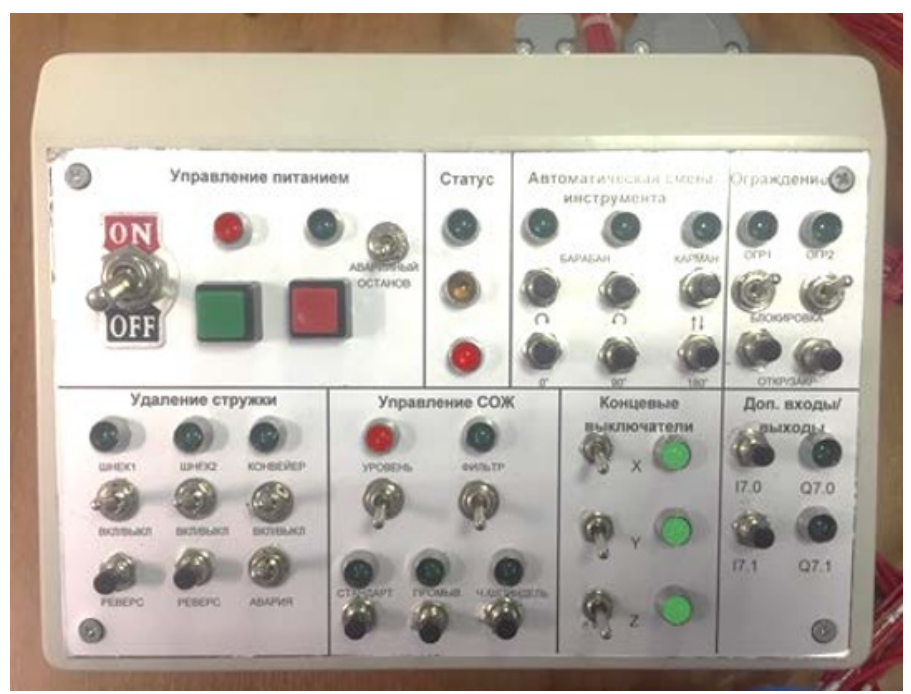

Fig. 6. Educational demonstration stand simulating the work of the machining center. 
The developed stand allows to check the work of the created program of electroautomatics for the processing center, as well as the operation of an additional terminal solution for monitoring and managing its main nodes.

The given example of practical application of the developed mechanism for creating additional terminal solutions proves the urgency of the task and demonstrates the possibilities of its use in the construction of modern enterprises that meet the concepts of smart production.

\section{Conclusion}

Research of features of construction of human-computer interaction in the management of complex machinery equipment has shown that it is often necessary to create and use the additional terminal solutions that can improve the level of representation of the flowing processing, to implement remote management and control.

The mechanism for creating additional terminal solutions presented in the work provides an opportunity to quickly create a human-machine interface for managing diverse technological equipment. The developed set of terminal components allows to realize the majority of logical control tasks, in particular, to control the operation of the object, and also to send control signals to it. In addition, the developed mechanism allows to increase the level of flexibility of the management system, giving its operators the opportunity to create additional terminal solutions for monitoring and controlling the process. This allows to simplify the process of start-up and commissioning of technological equipment, to increase the possibility of monitoring the operation of equipment and the level of informatization in the enterprise, since the developed mechanism also provides the possibility of transferring the received data to higher levels.

The given example of practical application of the developed mechanism on an example of the milling machining center Quaser MV184P, managed by the CNC system «AxiOMA Control», demonstrates its wide possibilities for solving the task of additional control and management of complex technological equipment. The application of the developed mechanism for educational purposes by developing terminal solutions for simulating the operation of technological equipment expands the possibilities for staff training and allows to fully check the operation of PLC programs and control algorithms even without the availability of necessary equipment.

\section{References}

1. Amandeep Kaur, Dipti Bansal, Monitoring and controlling of continue furnace line using PLC and SCADA, Wireless Networks and Embedded Systems (WECON), 5th International Conference on 14-16 Oct. 2016, 2016.

2. Martinov G.M., Nikishechkin P.A., Grigoriev A.S., Chervonnova N.Yu., Organization of the interaction of the main components in the CNC system "AxiOMA Control" for the integration of new technologies and solutions into it, Automation in the industry. 2015. №5. p.10-15.

3. Jorge E.Correa, NicholasToombs, Placid M.Ferreira, A modular-architecture controller for CNC systems based on open-source electronics, Journal of Manufacturing Systems, vol. 44, Part 2, July 2017, pp. 317-323, 2017.

4. Kovalev I.A., Nikishechkin P.A., Grigoriev A.S., Approach to Programmable Controller Building by its Main Modules Synthesizing Based on Requirements Specification for Industrial Automation, 2017 International Conference on Industrial Engineering, Applications and Manufacturing (ICIEAM), 16-19 May, 2017.p.1-4. 
5. Nikishechkin P.A., Kovalev I.A., Grigoriev A.S., Nikich A.N., Construction of a cross-platform system for the collection and processing of diagnostic information on the operation of process equipment in industrial enterprises, Automated technologies and production, 2016, №4 (14) .- P. 51-56.

6. Georgi M. Martinov, Sergey V. Sokolov, Lilija I. Martinova, Anton S. Grigoryev, Petr A. Nikishechkin, Approach to the Diagnosis and Configuration of Servo Drives in Heterogeneous Machine Control Systems, 8th International Conference, ICSI 2017 Fukuoka, Japan, July 27 - August 1, 2017 Proceedings, Part II, pp.586-594.

7. Nikishechkin P.A., Kovalev I.A., Grigoriev A.S., Nikich A.N., Cross-platform system for the collection and processing of diagnostic information on the operation of technological equipment, Vestnik MSTU Stankin, 2017, No. 1 (40, P. 94-98.

8. Nezhmetdinov R.A., Nikishechkin P.A., Pushkov R.L., Evstafieva S.V., Practical aspects of application of a software-implemented controller for controlling the electroautomatics of vertical milling machines Quaser MV184, Automation in Industry, №5. 2016. - P.14-17.

9. Nezhmetdinov R.A., Nikishechkin P.A., Pushkov R.L., Control of automatic tool change on multi-purpose machining centers with application of unified software solutions, Industrial Automated Control Systems and Controllers. No. 6, 2016. - P. 1924.

10. Petr A. Nikishechkin, Ilya A. Kovalev, Anatolii N. Nikich, An approach to building a cross-platform system for the collection and processing of diagnostic information about working technological equipment for industrial enterprises, MATEC Web Conf. Volume 129, 2017 (International Conference on Modern Trends in Manufacturing Technologies and Equipment (ICMTMTE 2017). 